\title{
New ST623 of Cryptococcus neoformans isolated from a patient with non-Hodgkin's lymphoma in the Brazilian Amazon
}

\author{
Lucyane Mendes Silva ${ }^{1,2}$, William Antunes Ferreira ${ }^{2,3}$, Roberto Alexandre Alves Barbosa Filho ${ }^{4}$, \\ Marcus Vinícius Guimarães Lacerda ${ }^{5,6}$, Guilherme Motta Antunes Ferreira ${ }^{1,2}$, Maria de Nazaré Saunier ${ }^{1}$, \\ Marielle Machado Macedo ${ }^{1,2}$, Denise de Almeida Cristo ${ }^{1,2}$, Marla Jalene Alves ${ }^{6}$, Ani Beatriz Jackisch-Matsuura ${ }^{6}$ \\ and Cristina Motta Ferreira ${ }^{1,2^{*}}$ (1)
}

\begin{abstract}
Background: Cryptococcosis is a disease of wide geographic distribution. It is most critical when it affects immunocompromised patients, with AIDS, tuberculosis or other diseases that require prolonged hospitalization.

Methods: This study described a case report, molecular epidemiology, the phylogenetic relationship, along with antifungal susceptibility test of a new ST 623 of C. neoformans isolated in a patient with non-Hodgkin's Lymphoma, from Manaus, Brazil.

Results: The new C. neoformans was susceptible to all antifungal drugs tested. Our results showed that ST623 new clone has no evident evolutionary proximity to any other ST of the VNI subtype group identified in Brazil.

Conclusions: In the context of phylogenetic analysis, this new genotype belongs to VNI subtype, and subsequencing complete genome studies are necessary to better understand the phylogenetic relationships amongst STs in this group.
\end{abstract}

Keywords: Phylogeny, C. neorformans, MLST, Non-Hodgkin disease, ST623

\section{Background}

Cryptococcosis is a serious disease possessing a wide geographic distribution, with a global burden of 957,900 cases of cryptococcal meningitis per year, resulting in 624,700 deaths [1]. This disease is an opportunistic mycosis caused by a complex called Cryptococcus neoformans and C. gattii [2], classified into four subtypes: VNI-VNII, VNIII, VNIV and VGI, VGII, VGIII, VGIV [3]. They are frequently isolated from bird excreta and trees hollows, penetrating the human host by inhaling infectious

*Correspondence: cris_motta_ferr@yahoo.com.br

${ }^{1}$ Fundação Hospitalar de Hematologia e Hemoterapia do AmazonasHEMOAM, Manaus, AM, Brazil

Full list of author information is available at the end of the article propagules [4], or through injured skin, causing different infections such as pulmonary cryptococcosis, nodules on the skin, meningitis or cryptococcal fungemia [3, 5-8].

In Latin America, there are records of 2400 deaths per year [9]. In countries like Colombia, the annual incidence is $2.4 /$ cases $/ 10^{6}$ inhabitants. In Mexico, the prevalence in patients with immunosuppression caused by different diseases is 21\%; while in Venezuela it is $19 \%$; and in Argentina, the prevalence is $20 \%$ [10]. In the city of Rio de Janeiro, Brazil, the annual incidence of cryptococcal meningitis is 0.45 cases $/ 10^{6}$ inhabitants, while in Northeastern Brazil; it is considered endemic [9]. Data from the Brazilian Ministry of Health evidence annual incidence of 7000 cases of cryptococcal meningoencephalitis [11].

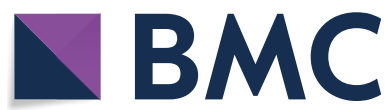

(c) The Author(s) 2020. This article is licensed under a Creative Commons Attribution 4.0 International License, which permits use, sharing, adaptation, distribution and reproduction in any medium or format, as long as you give appropriate credit to the original author(s) and the source, provide a link to the Creative Commons licence, and indicate if changes were made. The images or other third party material in this article are included in the article's Creative Commons licence, unless indicated otherwise in a credit line to the material. If material is not included in the article's Creative Commons licence and your intended use is not permitted by statutory regulation or exceeds the permitted use, you will need to obtain permission directly from the copyright holder. To view a copy of this licence, visit http://creativeco mmons.org/licenses/by/4.0/. The Creative Commons Public Domain Dedication waiver (http://creativecommons.org/publicdomain/ zero/1.0/) applies to the data made available in this article, unless otherwise stated in a credit line to the data. 
As it is considered an opportunistic mycosis, and potentially severe in certain patients, the availability of more sensitive tests for an enhanced routine laboratory diagnosis and treatment efficacy are indispensable for the proper control and monitoring of cryptococcosis. This rapid communications describes the molecular epidemiology, the phylogenetic relationships and the results of antifungal susceptibility test of a new ST (Sequencing Typing) from C. neoformans (ST 623).

This study was approved by the Foundation Human Research Ethical Committee (CEP/HEMOAM) under CAAE No 73548017.5.0000.0009, and all methods were performed in accordance with the relevant guidelines and regulations. Patients and a parent or guardian of any child participant enrolled in the study provided their written informed consent, before specimens were collected and the results and data were used for the management of each respective patient.

\section{Case report}

A 72 years old, retired farmer, living in the city of Manaus-Amazon-Brazil, sought care at the State Center of Reference in Dermatology-"Alfredo da Matta" Foundation; reported that he observed a tumor approximately $4 \mathrm{~cm}$ in diameter in the occipital region, among others distributed diffusely throughout the body. A posterior cervical lymph node biopsy was performed and he was diagnosed with non-Hodgkin lymphoma. During the same period, an abdomen scan was ordered, and he was referred to the Foundation Hospital of Hematology and Hemotherapy Blood Center of Amazonas (HEMOAM), a reference center for Onco-hematologic Diseases.

On May 06, 2017, he was treated at HEMOAM with generalized pruritus symptom and palpable liver. He was medicated with antihistamine and antipruritic. On July 06, 2017 after consultations with hematologists, blood tests were performed complementary to the diagnosis to start chemotherapy of LYMPHOMA. On Dezember 06, 2017 the patient presented: abdominal computed tomography (TC Abd): cervical region with expansive/ infiltrative lymph node mass, determining almost complete thrombosis of the left internal jugular vein + pulmonary emphysema + multiple mediastinal and axillary lymph node enlargement involving visceral/level and left internal mammary chain, retroperitoneal and mesenteric, inguinal, thoraco-lumbar and internal jugular vein thrombosis (tumor compression); and Hepatitis C (HCV) reagent. The patient was submitted to chemotherapy protocol from August 08, 2017 until October 10, 2017.

Still under the chemotherapy protocol for lymphoma, the patient presented a fever $37.5{ }^{\circ} \mathrm{C}\left(99.5{ }^{\circ} \mathrm{F}\right)$, coryza, sneezing, and elevation of transaminases with rates three times above normal limits. Subsequently, he attended the HEMOAM emergency room reporting weakness, a febrile peak of $38{ }^{\circ} \mathrm{C}\left(100.4{ }^{\circ} \mathrm{F}\right)$, vertigo, lack of appetite, nausea and epigastralgia. The laboratory findings were as follows: Haemoglobin (Hb): $12.6 \mathrm{~g} / \mathrm{L}$; Hematocrit (Ht) 36.8\%; Platelet: $101,000 / \mathrm{mm}^{3}$; neutrophil: $9.8 \%$; leucocyte: $2400 / \mathrm{mm}^{3}$; positive blood culture for Cryptococcus neoformans, and the diagnosis of Aplasia after chemotherapy. The patient was admitted for parenteral treatment with the antibiotics cefepime+clarithromycin and blood cultures were performed. However, due to his worsening clinical conditions, he was transferred to a University Hospital in Manaus on November 06, 2017.

Remaining in the ward of the University Hospital, the patient started treatment with Fluconazol $200 \mathrm{mg}$ for 14 days, after culture result identifying the presence of yeasts. The patient continued in the ward, with worsening clinical evolution of: pulmonary infection + Neurological syndrome (seizure absence?+disorientation + cognitive alteration) + Hydroelectrolytic disturbance (hypokalemia) + Intestinal constipation + Plaquetopenia. Cefepime and Clarithromycin empirically therapy was discontinued, substituted by the Meropenem antibiotic. From November 07, 2017 to November 09, 2017 the clinical condition evolved to cardio-respiratory arrest in Asystole, followed by resuscitation and transferred to the Intensive Care Unit (ICU); still critical under antibiotic therapy, another cardiac arrest on November 09, 2017 and, due to respiratory septic shock, evolved to death.

\section{Materials and methods}

\section{Laboratorial identification and antifungal susceptibility} test

Following the two positives blood cultures (BACT/ ALERT FA PLUS, Biomérieux, Brasil), the subculture was carried out in modified Sabouraud dextrose agar medium [12] and later in the media of canothothin-glycine blue bromothymol (CGB) and Niger Seed Agar for species differentiation. The phenotypic identification and minimum inhibitory concentration (MIC) values for fluconazole, amphotericin B and flucytosine were performed using VITEK-2 Compact equipment (bioMerieux, Brazil). Aliquots of the C. neoformans were stored at -80 degrees Celsisus $\left({ }^{\circ} \mathrm{C}\right)$, in a cryotube with Brain Heat Infusion Broth (BHI) (Himedia, Hexasystens-Mumbai, India) $+20 \%$ Glycerol for further molecular testing.

\section{Determination of molecular type}

DNA was extracted using DNeasy Blood \& Tissue Kit (Qiagen, Hilden, Germany) according to the manufacturer's instructions. The molecular identification of the fungus was determined applying the enzymatic restriction protocol (PCR-RFLP). The reaction for amplification of the gene was carried out in a 
reation volume of $25 \mu \mathrm{l}$. Each reaction contained $2 \mu \mathrm{l}$ of genomic DNA extract (28 ng); $2.5 \mu \mathrm{l}$ of $10 \times$ PCR buffer; $2.5 \mu \mathrm{l}$ of $\mathrm{MgCl} 2(50 \mathrm{mM}) ; 5 \mu \mathrm{l}$ of DNTp mix $(2.5 \mu \mathrm{M})$ (Invitrogen, Carlsbad, CA, USA); $0.5 \mu \mathrm{l}$ of the primers FW-5'-ATGTCCTCCCAAGC CCTCGA CTCCG-3'; SJ01-5'-TTAAGACCTCTGAACACC GCTCC-3' $(10 \mu \mathrm{M})$ and $0.5 \mu \mathrm{l}$ of Taq DNA polymerase $(5 \mathrm{U} / \mathrm{ml})$ (Invitrogen), Martins et al. [4]. Reactions were performed on a thermal cycler (Proflex PCR system, Applied Biosystems, Foster City, CA) at the following conditions: Initial denaturation at $95{ }^{\circ} \mathrm{C}$ for $5 \mathrm{~min}$, followed by 40 cycles at $95{ }^{\circ} \mathrm{C}$ for $5 \mathrm{~min}$; $95{ }^{\circ} \mathrm{C}$ for $45 \mathrm{~s}$; annealing at $55{ }^{\circ} \mathrm{C}$ for $45 \mathrm{~s}$ (ranging from $55^{\circ} \mathrm{C}, 56{ }^{\circ} \mathrm{C}, 56.5{ }^{\circ} \mathrm{C}$ to $57{ }^{\circ} \mathrm{C}$ ), extension at $72{ }^{\circ} \mathrm{C}$ for $2 \mathrm{~min}$, then final extension at $72{ }^{\circ} \mathrm{C}$ for $7 \mathrm{~min}$, Martins et al. [4].

The PCR product was demonstrated by $\mathrm{SYBR}^{\mathrm{TM}}$ safe (Invitrogen) DNA gel electrophoresis on $1.5 \%$ agar gels. Following this, sequencing was performed using the ABI PRISM 3130 XL Genetic Analyzer (Applied Biosystems, Foster City, CA), according to manufacturer's instructions. Sequences generated in the forward and reverse directions were read using Geneious v.11 software. A consensus sequence was extracted after being checked for discrepancies or mutations. The results were compared with the genomic DNA deposited in the site database (http://mlst.mycologyla b.org/). The analysis of Multilocus Sequence Typing (MLST) for C. neoformans was performed according to the site protocol (http://mlst.mycologylab.org/).

Sequences of the MLST genes from C. neoformans, isolated from HEMOAM, were compared with other VNI subtypes sequences, selected due to genetic proximity criterion that ST623 has with this group. The sequences of the subtype are deposited in the MLST database (http://mlst.mycologylab.org), totaling 174 samples. The nucleotide sequences of the seven alleles of the 174 samples were edited and aligned by the MEGA X program using the MUSCLE tool [13, 14]. The alignenment were analysed using MEGA $\mathrm{X}$ and DnaSP 6.0 programs. The phylogenetic tree were edited using ITOL program (https://itol.embl. de) [15]. To reconstruct the phylogenetic relationship between STs and VNI subtypes, the sequence of the seven MLST markers were concatened and analysed to choose the evolutive model 'Kimura 2 parameters' for analysis, with gamma distribution and invariable substitution rates. One tree underwent 1000 resamples per bootstrap. Pearson's correlation coefficient ( $r$ ) was used to analyze the correlation between nucleotide diversity and the number of MLST alleles, as well as the number of haplotypes and the MLST alleles.

\section{Results and discussion}

The microbiological test realized identified Cryptococcus neoformans. MIC showed susceptibility to all antifungal tested, with values of $1 \mu \mathrm{g} / \mathrm{ml}$ for fluconazole, $2 \mu \mathrm{g} / \mathrm{ml}$ for flucytosine and $0.5 \mu \mathrm{g} / \mathrm{ml}$ for amphotericin B. PCR-RFLP protocol identified the molecular type VNI, and comparative analyzes with the sequences deposited on the MLST website, made it possible to identify a new clone of Cryptococcus neoformans ST623. GenBank accession numbers of the $C$. neoformans allele from our case are MN065812, MN065813, MN065814, MN065815, MN065816, MN065817, and MN065818.

It was also observed that nucleotide diversity (Fig. 1) was higher when compared to all C. neoformans STs results studied by Muñoz et al. [16]. Of the seven genes analyzed, IGS1 presented the highest number of alleles (30) and highest nucleotide diversity (0.01864). The CAP53 presented the lowest values of alleles (13) and nuclotide diversity (0.0162).

A strong positive correlation of $r=0.80$ was observed between nucleotide diversity and the number of MLST alleles, as well as the number of haplotypes and the MLST alleles $(r=0.85)$. The fact that IGS1 corresponds to an intergenic region, contributes to the high nucleotide diversity observed in this region, characterizing it as a hypervariable marker, as described by Muñoz et al. [16, 17] (Fig. 1).

The analysis performed with the selected sequences for the evolutionary study of the new ST623 showed the ancestral relationship between monophyletic group (yellow) and the others groups studied. It was observed the proximity of ST623 and STs 341,142, 55, 264, 322, 54 and 84 , where these topologies are statistically supported by the high bootstrap values. It was also possible to reconstruct the ancestral relationship of the others monophyletic groups (green) formed by STs $145,153,147,143,145$ $, 184,144,149,148,182,171,152,151,183,150$ and the others STs of the VNI subtype. Our results showed also that ST623 clone, has no evident evolutionary proximity to any other ST of the VNI subtype group, identified in Brazil by Rocha et al. and Ferreira-Paim et al. [11, 18], from clinical and environmental samples, as can be observed in Fig. 2.

\section{Conclusions}

The new ST623 genotype was isolated from a patient with non-hodgkin's lymphoma, which evolved to death. In the evolutionary context of phylogenetic analysis, this genotype belongs to VNI subtype; however, the relationships between the STs in this group only can be elucidated after an approach with complete genome sequencing (WGS) studies. 


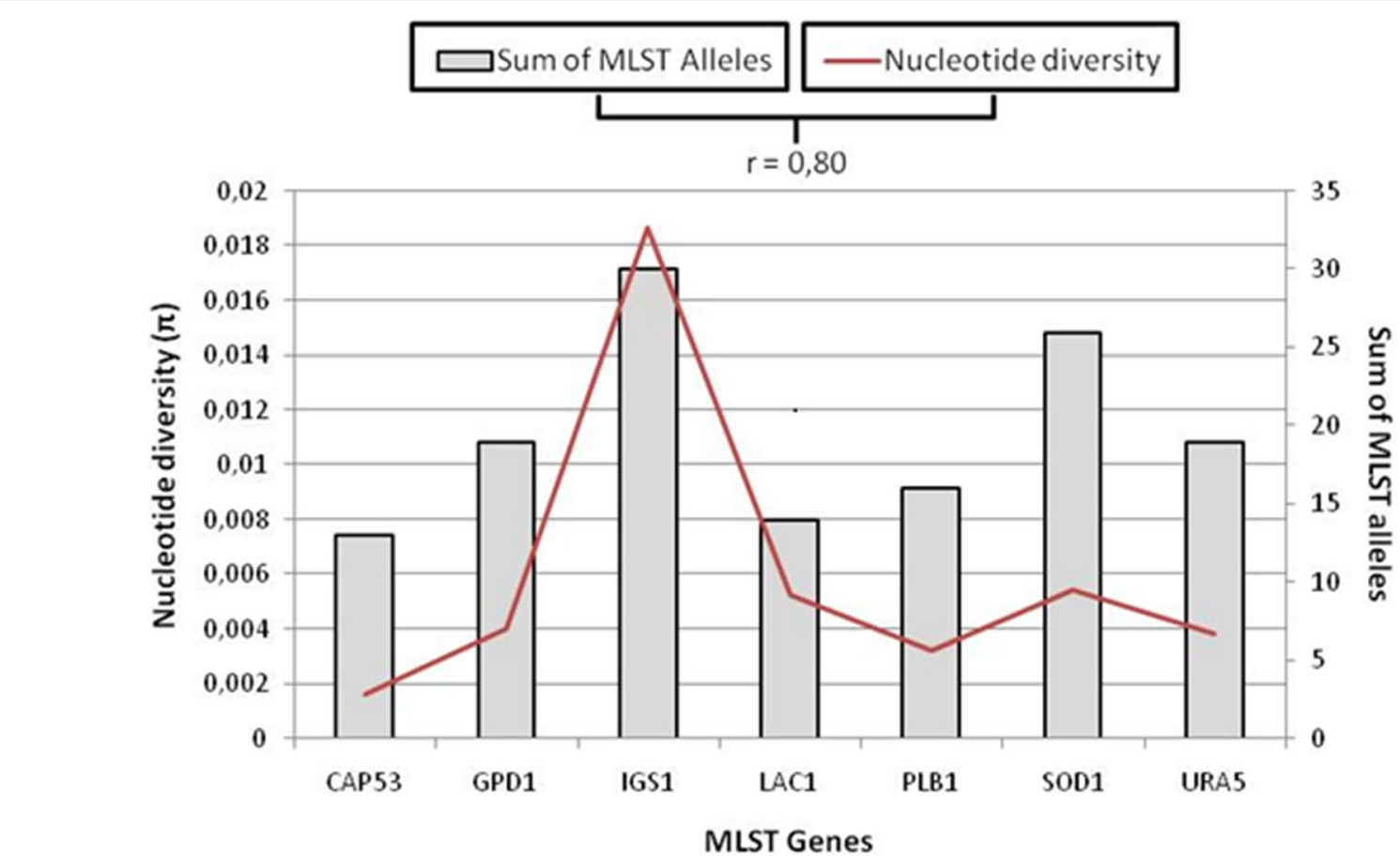

Fig. 1 Allelic diversity of VNI group

Tree scale: $0.1 \mapsto$
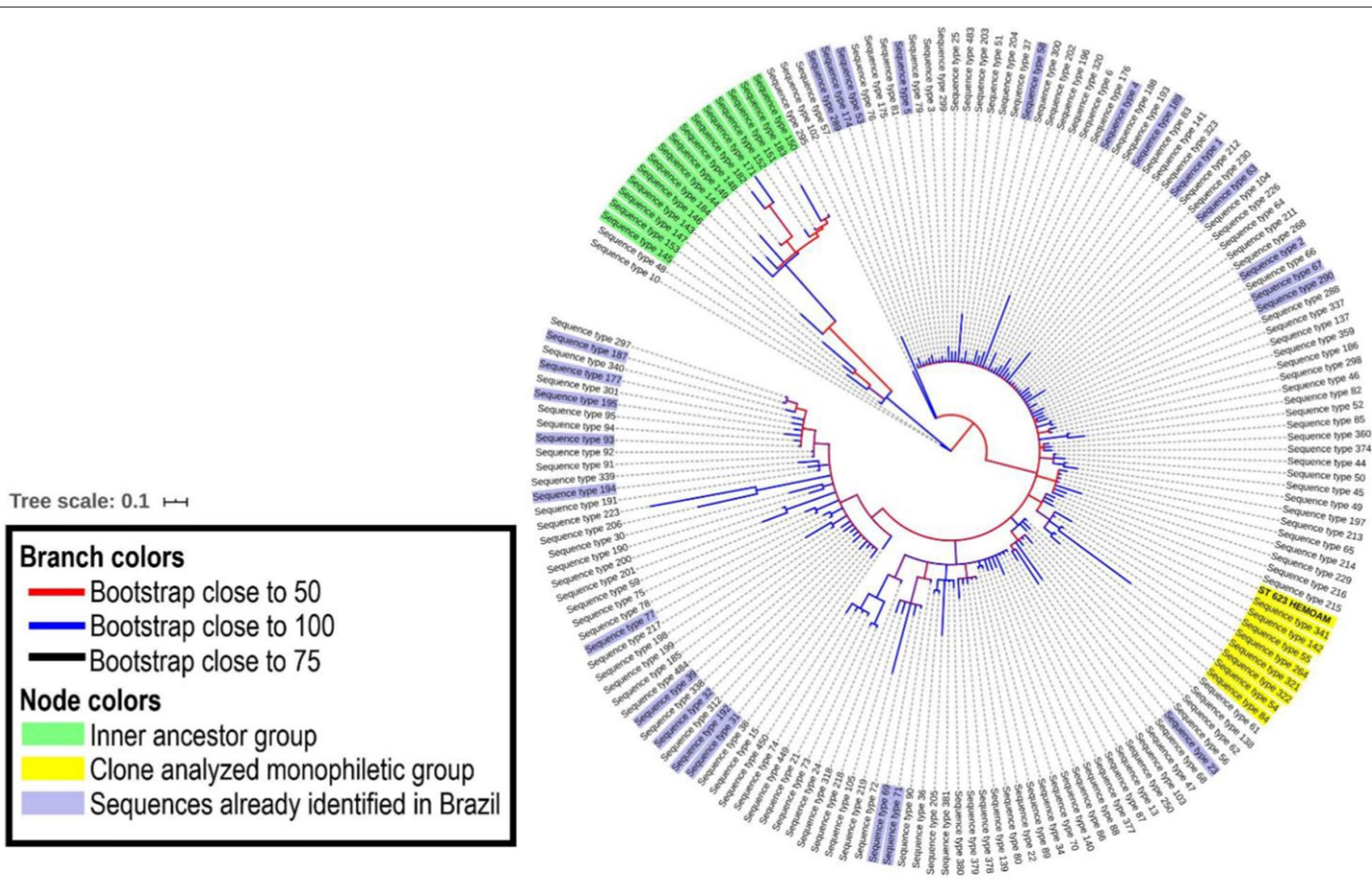

Fig. 2 Phylogenetic tree of the VNI subtype STs Groups. Branches in blue color represents groups with bootstrap near to 100. Branches in red color represents groups with bootstrap near to 50. The monophyletic group, containing ST623, is in yellow, and the green one is the internal ancestor group of the VNI subtype 


\begin{abstract}
Authors' contributions
Data Curation: LMS, RAABF, CMF, WAF; Investigation and Methodology: LMS, GMAF, MMM, DAC, MJA, ABJ-M, CMF, WAF; Software, formal analysis: RAABF, WAF; Visualization and Writing-Review \& Editing: WAF, CMF, RAABF, MVGL; Original draft preparation: WAF, RAAF, MAS, ABJ-M, CMF; Conceptualization, Funding acquisition, Project Administration, Resources: CMF, WAF. All authors read and approved the final manuscript.
\end{abstract}

\section{Funding}

The authors are grateful to acknowledge the support provided by the Amazonas State Research Foundation (FAPEAM) and Coordination for the Improvement of Higher Education Personnel (CAPES).

\section{Availability of data and materials \\ All data generated or analysed during this study are included in this published articleCode availability Not applicable.}

\section{Ethics approval and consent to participate}

This study was approved by the Foundation Human Research Ethical Committee (CEP/HEMOAM) under CAAE № 73548017.5.0000.0009, and all methods were performed in accordance with the relevant guidelines and regulations. Patients and a parent or guardian of any child participant enrolled in the study provided their written informed consent, before specimens were collected and the results and data were used for the management of each respective patient.

\section{Competing interests}

The authors report no competing interest. The authors alone are responsible for the content and the writing of the paper.

\section{Author details \\ ${ }^{1}$ Fundação Hospitalar de Hematologia e Hemoterapia do Amazonas- HEMOAM, Manaus, AM, Brazil. ${ }^{2}$ Universidade do Estado do Amazonas-UEA, Manaus, AM, Brazil. ${ }^{3}$ Fundação de Dermatologia Tropical e Venereologia Alfredo da Matta-FUAM, Manaus, Brazil. ${ }^{4}$ Universidade Federal do Amazonas- UFAM, Manaus, AM, Brazil. ${ }^{5}$ Fundação de Medicina Tropical Dr. Heitor Vieira Dourado, Manaus, AM, Brazil. ${ }^{6}$ Instituto Leônidas e Maria-Deane, FIOCRUZ, Manaus, AM, Brazil.}

Received: 19 February 2020 Accepted: 7 May 2020

Published online: 20 May 2020

\section{References}

1. Rajasingham R, Smith RM, Park BJ, Jarvis JN, Govender NP, Chiller TM, Denning DW, Loyse A, Boulware DR. Global burden of disease of HIVassociated cryptococcal meningitis: an updated analysis. Lancet Infect Dis. 2017;17:873-81.

2. Amburgy JW, Miller JH, Ditty BJ, Lune PV, Muhammad S, Fisher WS. Cryptococcus gattii in an immunocompetent patient in the
Southeastern United States. Case Rep Infect Dis 2016; 8280915. https:// doi.org/10.1155/2016/8280915

3. Meyer W, Castañeda A, Jackson S, Huynh M, Castañeda E. The IberoAmerican Cryptococcal Study Group. Molecular typing of Ibero American Cryptococcus neoformans isolates. Emerg Infect Dis. 2003;9:189-95.

4. Martins LMS, Wanke B, Lazéra MS, Trilles L, Barbosa GG, Macedo RCL, Cavalcanti MAS, Eulálio KD, Caastro JAF, Silva AS, Nascimento FF, Gouveia VA, Monte SJH. Genotypes of Cryptococcus neoformans and Cryptococcus gattii as agents of endemic cryptococcosis in Teresina, Piauí (northeastern Brazil). Mem Inst Oswaldo Cruz. 2011;106:725-30.

5. Lin Y-Y, Shiau S, Fang C-T. Risk factors for invasive Cryptococcus neoformans diseases: a case-control study. PLoS ONE. 2015;10:e 0119090.

6. Moreira LA, Batista SC, Gritti A, Silva JBM, Vido MHC. Meningoencefalite causada por Cryptococcus neoformans em pacientes portadores de HIV/ AIDS. Revista Educação em Foco. 2017;9:72-81.

7. Canavari IC, Vargas GH, Tinucci-Costa M, Camplesi AC. Criptococose: literature review. Revista eletrônica de veterinária. 2017;18:1-5.

8. Ellabib MS, Aboshkiwa MA, Husien WM, D'Amicis R, Cogliati M. Isolation, identification and molecular typing of Cryptococcus neoformans from Pigeon droppings and other environmental sources in Tripoli, Libya. Mycopathologia. 2016;81:603-8.

9. Leimann BC, Koifman RJ. Cryptococcal meningitis in Rio de Janeiro state, Brazil, 1994-2004. Cad Saude Publica. 2008;24:2582-92.

10. Firacative C, Lizarazo J, Illnait-Zaragozí MT, Castañeda E. Latin American Cryptococcal Study Group. The status of Cryptococcosis in Latin America. Mem Inst Oswaldo Cruz. 2018;113:1-23.

11. Rocha DFS, Cruz KS, Santos CSdS, Menescal LSF, Neto JRdS, Pinheiro SB, Silva LM, Trilles L, Souza JVB. MLST reveals a clonal population structure for Cryptococcus neoformans molecular type VNI isolates from clinical sources in Amazonas. Northern-Brazil. PLoS ONE. 2018;13:e0197841.

12. Ferreira CM, Andrade DR, Souza VS, Ferreira GMA, Ferreira WA. Effectiveness of modified sabouraud medium in relation to the bacterial growth. SOJ Microbiol Infect Dis. 2016;4(2):1-3.

13. Kumar S, Stecher G, Li M, Knyaz C, Tamura K. MEGA X: molecular evolutionary genetics analysis across computing platforms. Mol Biol Evol. 2018;35:1547-9.

14. Edgar RC. MUSCLE: multiple sequence alignment with high accuracy and high throughput. Nucleic Acids Res. 2004;32:1792-7.

15. Letunic I, Bork P. Interactive Tree Of Life (iTOL) v4: recent updates and new developments. Nucleic Acids Res. 2019;47:W256-9.

16. Muñoz M, Camargo M, Ramírez JD. Estimating the intra-taxa diversity, population genetic structure, and evolutionary pathways of Cryptococcus neoformans and Cryptococcus gattii. Front Genet. 2018;9:1-16.

17. Meyer W, Aanensen DM, Boekhout T, Cogliati M, Diaz MR, Esposto MC, Fisher M, Gilgado F, Hagen F, Kaocharoen S, Litvintsevas P, Mitchell TG, Simwami SP, Trilles L, Viviani MA, Chung JK. Consensus multi-locus sequence typing scheme for Cryptococcus neoformans and Cryptococcus gattii. Med Mycol. 2009;47(6):561-70.

18. Ferreira-Paim K, Andrade-Silva L, Fonseca FM, Ferreira TB, Mora DJ, Andrade-Silva J, Khan A, Dao A, Reis EC, Alemida MTG, Maltos A, Junior VR, Trilles L, Rickerts V, Chindamporn A, Sykes JE, Cogliati M, Nielsen K, Boekhout T, Fisher M, Chung JK, Engelthaler K, Lazera M, Meyer W, Vergara MLS. MLST Based population genetic analysis in a global context reveals clonality amongst Cryptococcus neoformans var. grubii VNI isolates from HIV patients in Southeastern Brazil. PLoS Negl Trop Dis. 2017;11:29.

\section{Publisher's Note}

Springer Nature remains neutral with regard to jurisdictional claims in published maps and institutional affiliations. 